\title{
BMJ Open Relationship between islet autoantibody status and the clinical characteristics of children and adults with incident type 1 diabetes in a UK cohort
}

\author{
Vassiliki Bravis, Akaal Kaur, ${ }^{1}$ Helen C Walkey, ${ }^{1}$ Ian F Godsland, ${ }^{1}$ Shivani Misra, ${ }^{1}$ \\ Polly J Bingley, ${ }^{2}$ Alistair J K Williams, ${ }^{2}$ David B Dunger, ${ }^{3}$ Colin M Dayan, ${ }^{4}$ \\ Mark Peakman, ${ }^{5}$ Nick S Oliver, ${ }^{1}$ Desmond G Johnston, ${ }^{1}$ on behalf of the \\ ADDRESS-2 Management Committee, Patient Advocate Group and Investigators
}

To cite: Bravis V,

Kaur A, Walkey HC, et al. Relationship between islet autoantibody status and the clinical characteristics of children and adults with incident type 1 diabetes in a UK cohort. BMJ Open 2018;8:e020904. doi:10.1136/ bmjopen-2017-020904

- Prepublication history for this paper is available online. To view these files, please visit the journal online (http://dx.doi. org/10.1136/bmjopen-2017020904).

Received 30 November 2017 Revised 7 February 2018 Accepted 1 March 2018

Check for updates

1Department of Medicine, Imperial College London, London, UK

${ }^{2}$ School of Clinical Sciences, University of Bristol, Bristol, UK ${ }^{3}$ Department of Paediatrics, University of Cambridge, Cambridge, UK

${ }^{4}$ School of Medicine, Cardiff University, Cardiff, UK

${ }^{5}$ Department of Immunobiology, King's College London, London, UK

Correspondence to

Dr Helen C Walkey;

h.walkey@imperial.ac.uk

\section{ABSTRACT}

Objectives To describe the characteristics of children and adults with incident type 1 diabetes in contemporary, multiethnic UK, focusing on differences between the islet autoantibody negative and positive.

Design Observational cohort study.

Setting 146 mainly secondary care centres across England and Wales.

Participants 3312 people aged $\geq 5$ years were recruited within 6 months of a clinical diagnosis of type 1 diabetes via the National Institute for Health Research Clinical Research Network. 3021 were of white European ethnicity and 291 (9\%) were non-white. There was a small male predominance $(57 \%)$. Young people $<17$ years comprised $59 \%$.

Main outcome measures Autoantibody status and characteristics at presentation.

Results The majority presented with classical osmotic symptoms, weight loss and fatigue. Ketoacidosis was common (42\%), especially in adults, and irrespective of ethnicity. 35\% were overweight or obese. Of the 1778 participants who donated a blood sample, $85 \%$ were positive for one or more autoantibodies against glutamate decarboxylase, islet antigen-2 and zinc transporter 8. Presenting symptoms were similar in the autoantibodypositive and autoantibody-negative participants, as was the frequency of ketoacidosis (43\%vs $40 \%, \mathrm{P}=0.3$ ). Autoantibody positivity was less common with increasing age $(\mathrm{P}=0.0001)$, in males compared with females (82\%vs90\%, $\mathrm{P}<0.0001)$ and in people of non-white compared with white ethnicity (73\%vs86\%, $\mathrm{P}<0.0001)$. Body mass index was higher in autoantibody-negative adults than autoantibody-positive adults (median, IQR 25.5, 23.1-29.2vs23.9, $21.4-26.7 \mathrm{~kg} / \mathrm{m}^{2} ; \mathrm{P}=0.0001$ ). Autoantibody-negative participants were more likely to have a parent with diabetes (28\%vs $16 \%, \mathrm{P}<0.0001)$ and less likely to have another autoimmune disease (4\%vs $8 \%$, $\mathrm{P}=0.01$ ).

Conclusions Most people assigned a diagnosis of type 1 diabetes presented with classical clinical features and islet autoantibodies. Although indistinguishable at an individual level, autoantibody-negative participants as a group demonstrated features more typically associated with other diabetes subtypes.

\section{Strengths and limitations of this study}

- We have studied a large multiethnic cohort of adults and children $\geq 5$ years with clinically diagnosed incident type 1 diabetes in whom pancreatic islet autoantibodies were measured in a central laboratory.

- In routine practice, the initial assignment of a diagnosis of type 1 diabetes is a purely clinical one. The lack of further selection before inclusion in this study (eg, based on autoantibody status and/or genetic testing) renders the results of particular relevance to standard clinical care.

- Individual autoantibody-positive and autoantibody-negative patients were indistinguishable clinically, but the size and diversity of the cohort permitted group differences to be detected at high levels of statistical significance, suggesting diagnostic heterogeneity.

- As this was a volunteer study recruiting from mainly secondary care centres, ascertainment bias could have been introduced.

- Provision of a blood sample was optional, and autoantibody status was therefore available in just over half of the patients. Other than having a higher median age, this subgroup was representative of the whole cohort.

Trial registration number ISRCTN66496918; Pre-results.

\section{INTRODUCTION}

Type 1 diabetes (T1D) is an autoimmune disease that develops at any age but most frequently in children and young adults. ${ }^{1}$ Autoantibodies against islet antigens are typically present before, and for a variable time following, diagnosis. ${ }^{2-6}$ Once initiated, beta cell damage classically leads to progressive loss of insulin secretion and a need for lifelong insulin treatment. 
The diagnosis of T1D is a clinical one but may be supported by the presence of one or more of the autoantibodies to islet cell antigens. In routine care, autoantibody status may not be available at diagnosis and may never be checked (management guidelines differ, with some not recommending their routine measurement or restricting measurements to situations where there is clinical doubt) ${ }^{7-9}$ Previous studies suggest that $80 \%-90 \%$ have detectable autoantibodies at disease onset, ${ }^{510}$ with a background autoantibody prevalence of around $2 \%$ in the young general population. ${ }^{11}$ Autoantibody positivity may be lower in some non-white ethnic groups. ${ }^{12-16}$ There is however uncertainty around the clinical and demographic correlates of autoantibody status in incident disease in an unselected multiethnic cohort including children and adults, using well characterised, validated assays. The After Diabetes Diagnosis REsearch Support System, supported by the National Institute for Health Research (NIHR) Clinical Research Network (CRN), recruits people with incident T1D from centres across England and Wales. We aimed to characterise these people with reference to their heterogeneity, focusing on the associations of autoantibody status with variation in presentation characteristics.

\section{METHODS}

\section{Ethics approval}

The project complies with the recommendations for research on human subjects by the 18th World Medical Assembly, Helsinki 1964 and later revisions and the International Conference on Harmonisation Guideline for Good Clinical Practice (Topic E6-10 June 1996). Protocol details have been reported previously ${ }^{17}$ and are therefore described in brief only.

\section{Inclusion and exclusion criteria}

People with a clinician-assigned diagnosis of T1D aged $\geq 5$ years were recruited within 6 months of diagnosis. Written informed consent was obtained for all participants.

\section{Data collection}

On recruitment: demographic information; medications including insulin(s); medical history, including that of autoimmune disease; family history of diabetes; blood pressure; weight and height; HbAlc; and fasting or random blood glucose. A diagnosis of ketoacidosis was recorded if clinically assigned or if hyperglycaemia was accompanied by acidosis and either ketonaemia or ketonuria. ${ }^{17}$ Ethnicity was self-reported as one of 16 categories. ${ }^{17}$

\section{Project-specific blood sampling and measurement of islet autoantibodies}

Sample donation was voluntary. ${ }^{17}$ Where collected, autoantibodies to glutamate decarboxylase (GADA), islet antigen-2 (IA-2A) and zinc transporter 8 (ZnT8A) were measured in sera using established radiobinding assays ${ }^{18} 19$ in a single central laboratory. Antibodies to both major ZnT8 isoforms, defined by the polymorphic amino acid at position 325 (arginine, ZnT8RA or tryptophan and ZnT8WA), were measured separately. Thresholds for autoantibody positivity were set at the 97 th percentile of 974 control samples for GADA, the 98th percentile of 500 control samples for IA-2A and the 97.5th percentile of 523 healthy schoolchildren for both ZnT8RA and ZnT8WA. Positive autoantibody status was defined as positive for one or more of GADA, IA-2A or either form of ZnT8A. In the 2015 Islet Autoantibody Standardization Program Workshop, the assay sensitivities and specificities achieved were $74 \%$ and $96.7 \%$ for GADA, $72 \%$ and $100 \%$ for IA-2A, $60 \%$ and $100 \%$ for ZnT8RA and $46 \%$ and $100 \%$ for ZnT8WA, respectively.

\section{Data analysis}

Children were defined as aged $<17$ years. Body mass index (BMI) was derived as a z-score for children using WHO (2007) reference data. ${ }^{20}$ As a criterion for adiposity shared between children and adults, we applied WHO-recommended definitions of 'normal' weight (z-score $<1$, equivalent percentile $<84.13 \%$ for children; BMI $<25 \mathrm{~kg} / \mathrm{m}^{2}$ for adults, both including underweight) as distinguished from 'overweight' ( $\mathrm{z}$-score $\geq 1$, percentile $\geq 84.13 \%$ for children, ${ }^{21} \mathrm{BMI} \geq 25 \mathrm{~kg} / \mathrm{m}^{2}$ for adults, ${ }^{22}$ both including obese). Parental and sibling history of diabetes was recorded. No attempt was made to differentiate between diabetes types in the family history. Variables were categorised as 'individual characteristics' and 'diabetes presentation'. We analysed data from participants recruited between 1 September 2011 and 30 April 2016, with data querying and verification completed in November 2016.

\section{Statistical analysis}

Statistical analysis was carried out using StataCorp 2013 (Stata Statistical Software: V.13). Median and IQRs were used to summarise continuous variables. Categorical variables were summarised as percentages. The MannWhitney $\mathrm{U}$ test and Kruskal-Wallis test were used for between-group comparisons of continuous variables. $\chi^{2}$ testing was used for comparisons of categorical variables. Individual characteristics were explored as predictors of diabetes presentation and antibody status in univariate logistic and linear regression analyses. Multiple logistic and linear regression were used to establish the independence of predictors. A significance level of $\mathrm{P}<0.05$ (two sided) was taken as a guide to interpretation (actual $\mathrm{p}$ values down to $\mathrm{P}<0.0001$ are reported throughout).

\section{Patient involvement}

Patient and public involvement groups within the NIHR CRN representing people with diabetes, and representing children and young people, had input into the design of the patient information sheets, consent forms and recruitment strategies. After the start of recruitment, 
Table 1 Clinical and demographic characteristics of the cohort $(n=3312)$

\begin{tabular}{|c|c|}
\hline & $\begin{array}{l}\text { Median (IQR)/ } \\
\text { percentage (n) }\end{array}$ \\
\hline \multicolumn{2}{|l|}{ Individual characteristics } \\
\hline Age (years) $(n=3312)$ & $14.6(10.4-26.4)$ \\
\hline Male $(n=3312)$ & $57(1879)$ \\
\hline Children $(<17$ years) $(n=3312)$ & $59(1946)$ \\
\hline \multicolumn{2}{|l|}{ Body mass index $(n=2911)$} \\
\hline Children ( $\mathrm{z}$ score, $\mathrm{n}=1676)^{\star}$ & $0.44(-0.28-1.23)$ \\
\hline Adult $\left(\mathrm{kg} / \mathrm{m}^{2}, \mathrm{n}=1235\right)$ & $24.1(21.5-27.1)$ \\
\hline Overweight or obese $(n=2911)$ & $35(1033)$ \\
\hline White European ethnicity $(n=3312)$ & $91(3021)$ \\
\hline $\begin{array}{l}\text { Other autoimmune disease present } \\
(\mathrm{n}=3270)\end{array}$ & $6(204)$ \\
\hline Parent(s) with any diabetes $(n=3261)$ & 15 (499) \\
\hline Sibling with any diabetes $(n=3003)$ & $8(229)$ \\
\hline \multicolumn{2}{|l|}{ Diabetes presentation } \\
\hline \multicolumn{2}{|l|}{ Clinical presentation } \\
\hline Ketoacidosis $(n=3242)$ & $42(1348)$ \\
\hline Osmotic symptoms $(\mathrm{n}=3286)$ & $96(3158)$ \\
\hline Weight loss $(n=3251)$ & $85(2753)$ \\
\hline Fatigue $(n=3252)$ & $82(2682)$ \\
\hline Symptom duration (weeks, $\mathrm{n}=3105$ ) & $3(2-6)$ \\
\hline Antibody positive $(n=1778)$ & $85(1510)$ \\
\hline
\end{tabular}

Sample sizes (n) are given for each variable if data collection was incomplete.

*The children's B MI z-score expressed as a percentile (median (IQR)) was $67 \%(39 \%-89 \%)(n=1676)$.

a patient advocate group was established to have input into aspects of study design and conduct, such as the procedures for accessing the data and stored biological samples, and communication with and engagement of participants, people with T1D and healthcare professionals. The group is made up of adults with T1D and the parents of children with T1D. Results are disseminated to participants via newsletters, and other information about the study is published on the study website and on social media.

\section{RESULTS}

\section{Overview of the cohort}

Individual characteristics

Data were analysed for 3312 participants recruited with incident T1D (1879 (57\%) males and 1946 (59\%) children from 146 centres; table 1). The slight male predominance $(57 \%)$ was more prominent in adults than in children $(61 \%$ vs $54 \%, \mathrm{P}<0.0001)$. Islet autoantibodies were measured in the 1778 participants who donated an optional blood sample. For individual characteristics, data recording was $>98 \%$ complete for all variables except BMI (and 'overweight': 88\%) and records of having a sibling with diabetes $(91 \%)$. Data recording for diabetes presentation features was $>98 \%$ complete for all variables except symptom duration $(94 \%)$. Sample sizes for incomplete data are reported in the tables. Of the total cohort, people of white European origin comprised 91\% ( $\mathrm{n}=3021)$, Asian (not Chinese) 3\% ( $\mathrm{n}=107)$, African-Caribbean 2\% ( $\mathrm{n}=63)$ and other or mixed ethnicity $3 \%(\mathrm{n}=121)$. Median time from diagnosis to recruitment was 71 days (IQR 40-119) and to blood sampling was 75 days (IQR 42-126). Of those with body weight measured $(n=2911), 35 \%$ were classified as overweight or obese, more commonly in adults than children $(41 \%$ vs $31 \%$, $\mathrm{P}<0.0001)$. Where records of body weight were available within 28 days of diagnosis $(\mathrm{n}=554), 35 \%$ were also overweight or obese (adults $40 \%$ vs children $29 \%, \mathrm{P}<0.005$ ).

Data collection for ketoacidosis at diabetes presentation was based on a record of it being assigned clinically or of hyperglycaemia accompanied by acidosis and either ketonaemia or ketonuria.

\section{The relationships between diabetes presentation and individual characteristics}

The main presenting features (table 1) were: osmotic symptoms (polyuria and/or polydipsia): 96\%, weight loss: $85 \%$, and fatigue: $82 \%$. Ketoacidosis was identified at clinical presentation in $42 \%$. Another autoimmune disease was present in $6 \%, 15 \%$ had a parent with diabetes and $8 \%$ had a sibling with diabetes.

\section{The influence of age}

Increasing age was independently associated with an increased prevalence of ketoacidosis, weight loss and fatigue at presentation, decreased prevalence of osmotic symptoms and longer symptom duration (figure 1). In accord with its relationship with age, ketoacidosis was less common in children than adults $(39 \%$ vs $45 \%$, $\mathrm{P}=0.0002)$. Although statistically significant, the differences between children and adults in other presenting symptoms were small (osmotic symptoms: $97 \%$ vs $95 \%$, $\mathrm{P}=0.001$; weight loss: $82 \%$ vs $89 \%, \mathrm{P}=0.0001$; fatigue: $78 \%$ vs $88 \%, \mathrm{P}=0.0001$, respectively), as were differences in symptom duration (median, 3 vs 4 weeks, $\mathrm{P}=0.0001$ ).

\section{The influence of gender}

Female sex was independently associated with longer symptom duration (figure 1). Median symptom duration in females and males were 4 and 3 weeks, respectively $(\mathrm{P}=0.0001)$.

\section{Associations with ethnicity}

There were no significant associations between ethnicity and initial clinical presentation, including ketoacidosis, which was equally likely: in white Europeans and non-whites ( $41 \%$ and $44 \%$, respectively; $\mathrm{P}=0.3$ ).

\section{Family history of diabetes}

Having a parent with any diabetes was associated with a lower probability of presenting with ketoacidosis (figure $1 ; 12 \%$ vs $18 \%, \mathrm{P}<0.0001$ ). The same applied to 


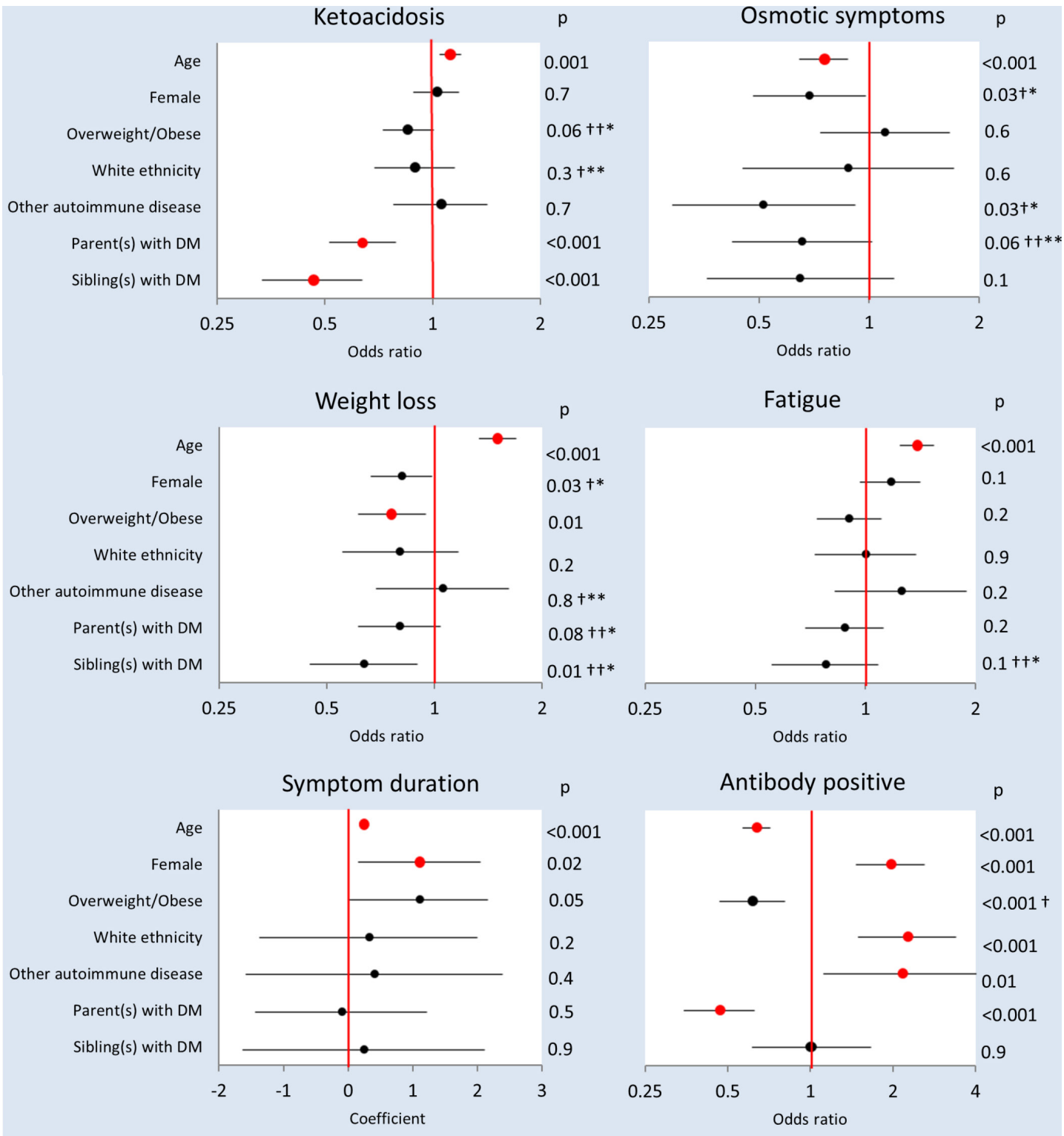

Figure 1 Individual characteristics as predictors of diabetes presentation and autoantibody status. Univariate logistic regression ORs or linear regression coefficients (circles), $95 \% \mathrm{Cls}$ (horizontal lines) ${ }^{\#}$ and statistical significances are shown. Red circles signify that a significant univariate relationship was sustained on multivariable analysis with all individual characteristics included as predictor variables (participants with complete data: $\mathrm{n}=2911-3312$ ) and in the subgroup with antibodies measured (participants with complete data including antibody status: $n=1610-1778) .{ }^{*}$ Not significant in subgroup with antibodies measured on multivariable analysis. ${ }^{*}$ Significant in subgroup with antibodies measured on multivariable analysis. $†$ Not significant on multivariable analysis. ††Significant on multivariable analysis. \#For 'Age', ORs or coefficients and 95\% Cls were derived from standardised data. DM, diabetes mellitus.

those who had a sibling with diabetes (figure $1 ; 5 \%$ vs $10 \%, \mathrm{P}<0.0001)$.

\section{Other autoimmune disease}

The presence or absence of another autoimmune disease had no significant influence on diabetes presentation.

\section{Description of the cohort in whom autoantibodies were measured}

Children comprised $38 \%$ of the subgroup of 1778 participants who provided a blood sample for autoantibody measurement. The subgroup with blood samples was, accordingly, significantly older than the full cohort (median (IQR) 21.6 (13.4-32.8) vs 14.6 (10.4-26.4) years, $\mathrm{P}<0.0001)$. Other parameters were similar. One or more autoantibodies were present in $85 \%$ of those who donated a blood sample.

The relationships between autoantibody status and individual characteristics

The influence of age

Autoantibody positivity decreased with increasing age; adults were less likely than children to be positive for one or more antibodies $(82 \%$ vs $90 \%, \mathrm{P}<0.0001)$. The decline in autoantibody positivity continued 


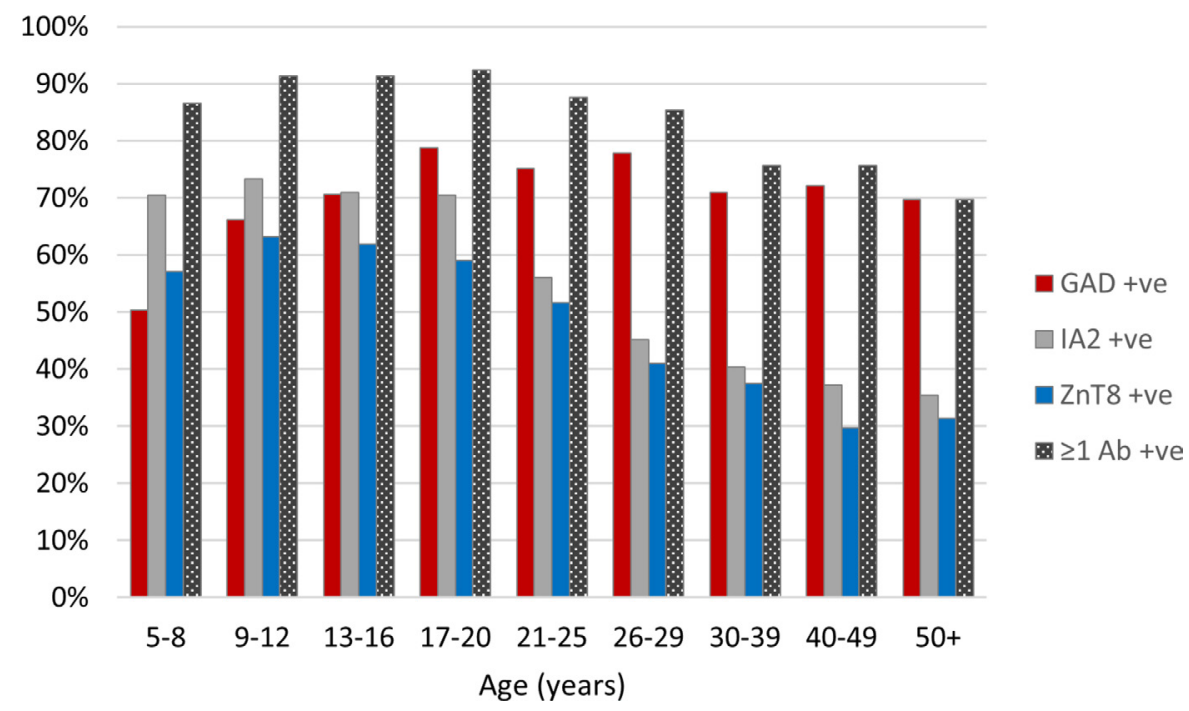

Figure 2 The percentage of participants exhibiting islet autoantibodies (any and individual) in relation to age at diagnosis. GAD, glutamate decarboxylase; IA2, islet antigen-2; ZnT8, zinc transporter 8.

throughout adult life (figure 2). Of the individual autoantibodies, GADAs were the most frequently observed in adults, with IA-2A and ZnT8A being relatively more common in children (figure 2). The autoantibody-positive adults were of lower BMI than autoantibody-negative adults (BMI, median (IQR) 23.9 (21.4-26.7) vs 25.5 (23.1-29.2), $\mathrm{P}<0.0001)$, and they were less likely to be overweight or obese $(40 \%$ vs $55 \%, \mathrm{P}=0.0001)$. No relationship to BMI z-score was observed in children, and there was no independent relationship between overweight/obesity and antibody positivity across children and adults (figure 1).

\section{The influence of gender}

Females were more likely than males to be antibody positive $(90 \%$ vs $82 \%$, respectively $(\mathrm{P}<0.0001)$.

\section{Associations with ethnicity}

There was a statistically significant relationship between ethnicity and autoantibody status (on $\chi^{2}$ analysis, $\mathrm{P}<0.0001$ ). Among the three major non-white ethnic groups (Asian, African-Caribbean and other or mixed ethnicity), numbers with autoantibodies measured were small $(n=46,36$ and 51 , respectively) and the proportion with autoantibody positivity did not differ significantly $(70 \%, 64 \%$ and $82 \%$, respectively; $\mathrm{P}=0.1$ ). People of non-white ethnic origin were therefore grouped, and comparisons were limited to white European versus non-white ethnic origin. White European ethnicity was independently associated with a higher prevalence of autoantibody positivity compared with the combined non-white group ( $86 \%$ and $73 \%$, respectively; $\mathrm{P}<0.0001$; figure 1).

\section{Family history of diabetes}

People who had a parent with diabetes were less likely than those without to have autoantibodies (figure 1; 16\% vs $28 \%, \mathrm{P}<0.0001$, table 2 ).

\section{Other autoimmune disease}

Another autoimmune disease was present in 204 participants and 117 of those in whom autoantibodies were measured. A history of another autoimmune disease was positively associated with pancreatic islet autoantibody positivity ( $\mathrm{P}=0.01$, figure 1 ), being present in $8 \%$ of the autoantibody-positive participants and $4 \%$ of the autoantibody-negative participants (table 2).

\section{The relationship between autoantibody status and diabetes presentation}

A statistically significant relationship between positive autoantibody status and diabetes presentation was restricted to a very small increase in prevalence of osmotic symptoms ( $97 \%$ vs $94 \%, \mathrm{P}=0.02$, table 2 ). There was no significant difference in rates of ketoacidosis at presentation between autoantibody-positive and autoantibody-negative participants ( $43 \%$ vs $40 \%, \mathrm{P}=0.3$, table 2 ).

\section{DISCUSSION}

For the first time, relationships between autoantibody status (measured centrally in a single reference laboratory) and phenotypic features in incident T1D are reported from a large, unselected, multiethnic population of both children and adults. The study was conducted with support from the NIHR CRN with most participants recruited from specialist centres. Based on estimates of T1D incidence and population demographics, ${ }^{23} 2420 \%-$ $25 \%$ of eligible incident cases in England and Wales were recruited.

Male predominance is unusual for an autoimmune condition but has been reported in adults with incident T1D. ${ }^{25}$ In young children, the sex ratio has been reported to be close to unity. ${ }^{26}$ In the present study, the male excess was observed also in children, although the excess was less marked than in adults. Symptoms at presentation were as 
Table 2 Characteristics of pancreatic autoantibody (Ab) positive and negative participants $(n=1778$ with known antibody status)

\begin{tabular}{|c|c|c|c|}
\hline & Ab positive $(n=1510)$ & Ab negative $(n=268)$ & $P$ values \\
\hline \multicolumn{4}{|l|}{ Individual characteristics } \\
\hline Age & $20.1(13.1-31.1)$ & $31.4(17.7-41.0)$ & 0.0001 \\
\hline Male & $56(851)$ & $72(192)$ & $<0.0001$ \\
\hline Children & $41(614)$ & $25(66)$ & $<0.0001$ \\
\hline \multicolumn{4}{|l|}{ Body mass index } \\
\hline Children (z score, $n=545,56)^{*}$ & $0.41(-0.35$ to 1.19$)$ & $0.47(-0.48$ to 0.97$)$ & 0.4 \\
\hline Adult $\left(\mathrm{kg} / \mathrm{m}^{2}, \mathrm{n}=825,184\right)$ & $23.9(21.4-26.7)$ & $25.5(23.1-29.2)$ & 0.0001 \\
\hline Overweight $(n=1370,240)$ & $36(490)$ & $48(114)$ & 0.0005 \\
\hline White European ethnicity & $86(1413)$ & $14(232)$ & $<0.0001$ \\
\hline Other autoimmune disease $(n=1495,265)$ & $8(117)$ & $4(10)$ & 0.01 \\
\hline Parent(s) with any diabetes $(n=1493,261)$ & $16(233)$ & $28(74)$ & $<0.0001$ \\
\hline Siblings with any diabetes $(n=1374,238)$ & $9(117)$ & $8(20)$ & 0.9 \\
\hline \multicolumn{4}{|l|}{ Diabetes presentation } \\
\hline \multicolumn{4}{|l|}{ Clinical presentation } \\
\hline Ketoacidosis $(n=1483,260)$ & $43(639)$ & $40(104)$ & 0.3 \\
\hline Osmotic symptoms $(n=1495,267)$ & $97(1444)$ & $94(250)$ & 0.02 \\
\hline Weight loss $(n=1480,267)$ & $87(1285)$ & $88(235)$ & 0.5 \\
\hline Fatigue $(n=1490,265)$ & $86(1282)$ & $80(213)$ & 0.01 \\
\hline Symptom duration (weeks, $n=1424,246$ ) & $6.8(10.5)$ & $10.4(32.2)$ & 0.004 \\
\hline
\end{tabular}

Percentages ( $n$ ) or medians (IQR) are shown.

Sample sizes ( $n$ ) are given for each variable if data collection was incomplete.

${ }^{*}$ The children's BMI z-scores expressed as percentiles (median (IQR)) were 66\% (36\%-88\%) in the autoantibody positive ( $\left.n=545\right)$ and $68 \%$ $(32 \%-83 \%)$ in the autoantibody negative $(n=56)$.

${ }^{* *}$ Median and IQRs for symptom duration were identical: 4 (2-8); mean and SD is shown to clarify the direction of difference.

expected. ${ }^{27}{ }^{28}$ Although weight loss was common, average body weight at the time of recruitment was normal, and many participants were overweight or obese, especially adults. This was apparent even in people with body weight measurements obtained within 28 days of diagnosis, belying the belief that patients presenting with T1D are underweight. An association between increased BMI and increased risk of progression from autoantibody positivity to development of diabetes in at-risk relatives has been reported previously. ${ }^{29}$ Symptom duration was similar to that reported previously by others and was shorter in children than adults. ${ }^{30} 31$ This may reflect parental vigilance of unwell children or a more insidious onset of clinical disease in older people.

The overall frequency of ketoacidosis at diagnosis (42\%) was high and slightly more so in adults than children. It occurred with similar frequency in white European and non-white ethnic groups. The figure of $42 \%$ is higher than in previous reports from the UK $(23 \%$ in a recent national paediatric audit, ${ }^{32} 26 \%-27 \%$ in regional studies ${ }^{3334}$ ), and a range of $13 \%-80 \%$ in those aged $<20$ years has been reported internationally. ${ }^{35}$ A very similar figure $(40.3 \%)$ has been reported recently for children in Italy. ${ }^{36}$ Ketoacidosis at diagnosis is a quality issue as it reflects lack of awareness of diabetes features among professionals and the general population, ${ }^{32}$ and efforts to increase awareness lead to reductions in ketoacidosis at first presentation. ${ }^{37}$ All methods of estimating the frequency of ketoacidosis at diagnosis have limitations, often leading to under-reporting. ${ }^{32}$ Strengths of the current study include the large number of patients and the ability to confirm or refute the diagnosis where this was in doubt. A limitation is that ascertainment bias could be introduced because recruitment was mainly from secondary care, and those who are the most ill at diagnosis may be the most likely to volunteer or to be referred. The higher ketoacidosis rate in adults versus children in our study appears at variance with the observation that ketoacidosis or severe ketoacidosis is more common in younger than in older children. $^{28} 3336$ 38-40 The current study did not include children $<5$ years of age, the group in childhood in whom ketoacidosis at diagnosis occurs most frequently, ${ }^{41}$ and this may have contributed to the apparent children to adult difference. Of course, if such younger children had been included, this could have increased the overall rate of ketoacidosis even higher. The lower rate associated with having a parent or a sibling with diabetes could result from a heightened awareness of symptoms leading to earlier clinical referral. ${ }^{35}$ The absence of any significant ethnic influence on ketoacidosis is at variance with 
some previous reports where higher rates were observed in non-white subgroups. ${ }^{42} 43$

One or more islet autoantibodies were observed in $85 \%$ of participants, more commonly in female than male and in younger compared with older participants. This is compatible with previous literature from the UK and other countries, ${ }^{84-46}$ although assay differences make such comparisons difficult. The positivity rate is higher than reported in people with T1D of non-white ethnic origin, ${ }^{12}{ }^{13}$ although with the same caveats and bearing in mind that the previous studies of ethnic influences on antibody status have been limited in size or age range of population studied. The slight female autoantibody preponderance has been observed in other studies in young children, but not in older children and young adults. ${ }^{47}$ The higher autoantibody frequency in those with a coexistent autoimmune disease reflects the clustering of autoimmune disorders observed in T1D and shared genetic susceptibility. ${ }^{48}$ Overall, GADAs were the antibodies most commonly present, while IA-2A and ZnT8A were seen most frequently in children, findings compatible with previous studies. ${ }^{47}$ Insulin itself is considered a potential primary autoantigen as insulin autoantibodies are observed in incident T1D, especially in children. ${ }^{30} 3149$ In the current study, most participants had received insulin therapy for weeks before study entry, and as they could have developed antibodies to the exogenous insulin, insulin autoantibodies were not measured. In prospective studies of infants at high genetic risk of T1D, insulin autoantibodies were often detected earlier than the other islet autoantibodies, ${ }^{50}$ and in consequence, we may have underestimated the frequency of autoantibody positivity at diagnosis, especially in children.

Although autoantibodies can be present for years in people with diabetes who do not require insulin treatment immediately ${ }^{5-54}$ and are present in some diagnosed clinically with type 2 diabetes ${ }^{55}$ they are generally regarded as a biomarker for T1D. In prospective studies they precede and predict the onset of T1D. ${ }^{56}$ They typically disappear, or titres drop to very low levels, in the years following diagnosis. ${ }^{57}$ In the autoantibody-negative participants studied here, several explanations may be proposed. First, insulin autoantibodies were not measured. Second, autoantibodies to as yet unknown antigens may have been present. ${ }^{58}$ The identification of tetraspanin-7 as an autoantigen could, for example, account for some apparently antibody-negative participants, ${ }^{59}$ although recent data suggest this is unlikely to account for large numbers. ${ }^{60}$ Third, autoantibodies may have disappeared or their levels diminished by the time of sampling. As all participants were recruited within 6 months of diagnosis, this is unlikely to be a major factor. Fourth, autoantibodies might develop subsequently, as reported previously for islet cell antibodies in a small proportion of patients. ${ }^{61}$ Fifth, some people may have autoimmune T1D without a humoural response. Finally, people may actually have another diabetes subtype. The autoantibody-negative participants as a group tended to be older and, if adult, more overweight. These features are compatible with type 2 diabetes. They were more likely to have a parent with diabetes, typical of type 2 or monogenic diabetes. They were more likely to be of non-white ethnicity, more associated with type 2 diabetes. Those with ketoacidosis could have ketosis-prone diabetes (so-called idiopathic diabetes $)^{62}$ as this is difficult to distinguish from T1D at first presentation. Further studies and follow-up of the cohort are planned to explore the extent to which T1D without detectable autoantibodies describes a subgroup of T1D that is distinct from other diabetes subtypes.

Acknowledgements We are grateful to Nish Chaturvedi and Joanne Holloway, who provided much advice and support at the initiation of the project and to Simon Howell for chairing the Management Committee. We thank the ADDRESS-2 Patient Advocate Group for their input into aspects of study design and conduct. We also thank Kyla Chandler, Claire Williams and antibody laboratory technicians at the University of Bristol for the assay of islet autoantibodies, Flora Christofi for study administrative support at Imperial College London and all the local research teams at participating centres. We are grateful to colleagues, George Alberti, Robert Elkeles, Rochan Agha-Jaffar, Ahmed El-Laboudi, Neil Hill, Monica Reddy and Shivshankar Seechurn for their critical review of early analyses of the results.

Collaborators AbithaKujambal V; Abouglila K; Ahmed J; Ahmed K; Ahmed M; Ahmed Z; Ajjan R; Akiboye F; Ali A; Ali K; Anand B; Anderson C; Andrews R; Anjum B; Anthony S; Aung T; Ayoola 0; Baburaj R; Bain S; Baker E; Baksi A; Banerjee K; Banerjee M; Barnes D; Barnet A; Baynes K; Bellary S; Bennett S; Besser R; Bhardwaj P; Bhattacharya B; Bhimsaria S; Bickerton A; Bilous R; Bingham E; Bodmer C; Bridges N; Brooks A; Browne D; Buck J; Cackett N; Caldwell G; Campbell F; Carey P; Cavan D; Chandran S; Chandrasakaren S; Chang J; Chankramath A; Chant T; Chapman J; Chattington P; Chenoweth H; Chetan R; Chong J; Choudhary P; Cifelli P; Clark J; Cliff P; Coldwell S; Cooper C; Coppini D; Creely S; Cronin M; Cummings M; Dang C; Darzy K; Dashora U; Davies J; Davies M; Davies R; Day P; De Silva P; DelRio A; Delrio A; Desilva P; Dornhorst A; Douek I; Dougherty I; Dukhan K; Durkin S; Dutta A; Dutta S; Earle K; Edge J; Edmonds C; Edwards M; Elmati A; El-Refee S; Elrishi M; Evans M; Field B; Flanagan D; Franke B; Gable D; Galliford T; Ganapathi J; Gibbs J; Gibson M; Gnudi L; Gough A; Gough S; Goulden P; Govier K; Greening J; Gupta A; Gupta S; Gurnell E; Hamilton-Shield J; Hammond P; Han T; Hanna F; Hanson P; Haq M; Hardy K; Harms B; Hattersley A; Hayward J; Heald A; Heffernan H; Heller S; Hinde F; Hitman G; Holt H; Howell S; Huma Z; Hyer S; Ian 0; Idris I; ljaz S; Iqbal N; Issa B; Jackson A; Jackson A; Jain N; Jennings P; John K; Johnson R; Jones S; Joseph F; Joseph J; Joseph S; Kalathil S; Kanumilli N; Kapoor R; Karandikar S; Kelly P; Kershaw M; Khetriwal B; Kumar K; Laji K; Lakhdar A; Lawrence J; Leong K; Levy D; Lowe A; Lyder G; Macklin A; Mallam K; Mallik R; Mann N; Mansell P; Margabanthu G; Massoud A; Mathew V; McAulay A; McCowen E; McCrea K; McGuigan M; Medici F; Mettayill J; Millward A; Mitchell C; Modgil G; Mohanty R; Moodambail A; Mosely A; Moudiotis C; Muhi-Iddin N; Mukhtar M; Murphy N; Muzulu S; Myint K; Nagi D; Naik S; Narendran P; Natarajan A; Nathan Y; Nayar R; Ng M; Ngwu U; Nikookam K; O'Connell I; Oelbaum R; O'Hare P; Oliver N; O'Malley B; Oso 0; Overend L; Owen C; Owen K; Padinjakara N; Pai B; Pang T; Pargass N; Patel K; Pathy K; Paul P; Paul Smith J; Peakman M; Petit A; Pettit A; Piel B; Pope R; Pothina N; Pothina N; Price H; Purewal T; Puthi V; Puttha R; Puttha R; Rabbi T; Raffeeq P; Rahman S; Ranashinghe A; Randell T; Rathi S; Rawal S; Rayman G; Regan F; Rice S; Riddle M; Robertson E; Robinson M; Russell-Jones D; Russell-Taylor M; Rutter M; Sampson M; Samuel J; Sankar S; Sankar V; Saravanan P; Satish H; Savine R; Scanlon J; Scobie I; Sennik D; Sharpe R; Shekar S; Shekhar S; Simon G; Simpson H; Singh B; Singhal P; Smith D; Smith J; Smith P; Solomon H; Srinivasan B; Sriraman R; Stirling H; Strutt J; Surridge A; Sutchfield P; Tatnell S; Tharian K; Timmis A; Trevelyan N; Turner B; Valabhji J; Venkatesh U; Vijayaraghavan $\mathrm{S}$; Vijayaraman A; Vithian K; Vora J; Waldron-Lynch F; Walker M; Walmsley D; Ward W; Watt A; Weaver J; Webber J; Weerasinghe K; West N; Whitehead P; Whitelaw D; Wickramasuriya N; Wilding J; Williams P; Williams S; Winkley K; Wright N; and Yaliwal C; Yarlagadda S; Zac-Varghese S.

Contributors Literature searches were carried out by VB, HCW, IFG, NSO and DGJ. AK, HCW, IFG, AJKW, PJB, DBD and DGJ were involved in the study design. Data collection was coordinated by AK and HCW. AK, HCW and IFG were responsible for data management. AJKW and PJB were responsible for autoantibody measurements. The statistical analysis plan was developed by IFG. Analysis of the data was by VB, AK and IFG. Data were interpreted by all authors. The manuscript 
was prepared by authors VB, AK, HCW, IFG, AJKW and DGJ. Critical revisions were made by authors PJB, DBD, CMD, MP and NSO. Figures were prepared by AK, HCW and IFG. The Management Committee oversaw access to the data and stored biological samples. The Patient Advocate Group had input into aspects of study conduct. Local investigators were responsible for the recruitment of participants and collection of data. HCW is the guarantor of this study.

Funding The National Institute for Health Research (NIHR) provided the funding for the research infrastructure of the national Clinical Research Network (CRN), with project- specific support from Diabetes UK (grant numbers 09/0003919 and 15/0005234) and the Juvenile Diabetes Research Foundation (grant numbers 9-2010-407 and 3-SRA-2015-36-A-N). The funders were consulted about the vision for a UK-based type 1 diabetes ascertainment network. The funders are represented on the management committee that oversees access to the data and stored biological samples. The funding was administered as a grant to Imperial College London. Imperial College London is the study Sponsor.

Disclaimer The funders had no involvement in study design, data collection, data analysis, data interpretation or writing of the article and took no part in the decision to submit for publication.

Competing interests None declared.

Patient consent Not required.

Ethics approval Ethical approval was obtained from the South Central - Berkshire NHS Research Ethics Committee (reference 10/H0505/85).

Provenance and peer review Not commissioned; externally peer reviewed.

Data sharing statement The full anonymous dataset is available to access via a management committee, which includes people living with type 1 diabetes, scientists, clinicians and funder representatives as members. Participants gave informed consent for data sharing subject to conditions described in the access procedure documents available from the study website: www.address2.org.

Open Access This is an Open Access article distributed in accordance with the Creative Commons Attribution Non Commercial (CC BY-NC 4.0) license, which permits others to distribute, remix, adapt, build upon this work non-commercially, and license their derivative works on different terms, provided the original work is properly cited and the use is non-commercial. See: http://creativecommons.org/ licenses/by-nc/4.0/

(c) Article author(s) (or their employer(s) unless otherwise stated in the text of the article) 2018. All rights reserved. No commercial use is permitted unless otherwise expressly granted.

\section{REFERENCES}

1. Todd JA. Etiology of type 1 diabetes. Immunity 2010;32:457-67.

2. Palmer JP, Asplin CM, Clemons P, et al. Insulin antibodies in insulin-dependent diabetics before insulin treatment. Science 1983;222:1337-9.

3. Bonifacio E, Genovese S, Braghi S, et al. Islet autoantibody markers in IDDM: risk assessment strategies yielding high sensitivity. Diabetologia 1995;38:816-22.

4. Graham J, Hagopian WA, Kockum I, et al. Genetic effects on age-dependent onset and islet cell autoantibody markers in type 1 diabetes. Diabetes 2002;51:1346-55.

5. Wenzlau JM, Juhl K, Yu L, et al. The cation efflux transporter ZnT8 (Slc30A8) is a major autoantigen in human type 1 diabetes. Proc Nat Acad Sci U S A 2007;104:17040-5.

6. Tridgell DM, Spiekerman C, Wang RS, et al. Interaction of onset and duration of diabetes on the percent of GAD and IA-2 antibodypositive subjects in the type 1 diabetes genetics consortium database. Diabetes Care 2011;34:988-93.

7. Chiang JL, Kirkman MS, Laffel LM, et al. Type 1 diabetes through the life span: a position statement of the American Diabetes Association. Diabetes Care 2014;37:2034-54.

8. National Institute for Health and Care Excellence. Type 1 diabetes in adults: diagnosis and management. NICE guideline 2015.

9. National Institute for Health and Care Excellence. Diabetes (type 1 and type 2) in children and young people: diagnosis and management. NICE guideline 2015.

10. Hameed S, Ellard S, Woodhead HJ, et al. Persistently autoantibody negative (PAN) type 1 diabetes mellitus in children. Pediatr Diabetes 2011;12:142-9.

11. Knip M, Korhonen S, Kulmala P, et al. Prediction of type 1 diabetes in the general population. Diabetes Care 2010;33:1206-12.
12. Libman IM, Pietropaolo M, Arslanian SA, et al. Evidence for heterogeneous pathogenesis of insulin-treated diabetes in black and white children. Diabetes Care 2003;26:2876-82.

13. Dabelea D, Pihoker C, Talton JW, et al. Etiological approach to characterization of diabetes type: the SEARCH for Diabetes in Youth Study. Diabetes Care 2011;34:1628-33.

14. Black MH, Lawrence JM, Pihoker C, et al. HLA-associated phenotypes in youth with autoimmune diabetes. Pediatr Diabetes 2013;14:121-8.

15. Wenzlau JM, Frisch LM, Hutton JC, et al. Changes in zinc transporter 8 autoantibodies following type 1 diabetes onset: the type 1 diabetes genetics consortium autoantibody workshop. Diabetes Care 2015;38(Suppl 2):S14-20.

16. Dzidzonu DK, Skrivarhaug T, Joner G, et al. Ethnic differences in the incidence of type 1 diabetes in Norway: a register-based study using data from the period 2002-2009. Pediatr Diabetes 2016;17:337-41.

17. Walkey HC, Kaur A, Bravis V, et al. Rationale and protocol for the After Diabetes Diagnosis REsearch Support System (ADDRESS): an incident and high risk type 1 diabetes UK cohort study. BMJ Open 2017;7:e013956.

18. Bonifacio E, Yu L, Williams AK, et al. Harmonization of glutamic acid decarboxylase and islet antigen-2 autoantibody assays for national institute of diabetes and digestive and kidney diseases consortia. $J$ Clin Endocrinol Metab 2010;95:3360-7.

19. Long AE, Gooneratne AT, Rokni S, et al. The role of autoantibodies to zinc transporter 8 in prediction of type 1 diabetes in relatives: lessons from the European Nicotinamide Diabetes Intervention Trial (ENDIT) cohort. J Clin Endocrinol Metab 2012;97:632-7.

20. de Onis M, Onyango AW, Borghi E, et al. Development of a WHO growth reference for school-aged children and adolescents. Bull World Health Organ 2007;85:660-7.

21. de Onis M, Lobstein T. Defining obesity risk status in the general childhood population: which cut-offs should we use? Int J Pediatr Obes 2010;5:458-60.

22. WHO. Physical status: the use and interpretation of anthropometry. Report of a WHO expert Committee. WHO Technical Report Series. Geneva: World Health Organisation, 1995.

23. Patterson $\mathrm{CC}$, Dahlquist GG, Gyürüs $\mathrm{E}$, et al. Incidence trends for childhood type 1 diabetes in Europe during 1989-2003 and predicted new cases 2005-20: a multicentre prospective registration study. Lancet 2009;373:2027-33.

24. Office for National Statistics. 2011 Census: Aggregate data (England and Wales) [computer file]. UK Data Service Census Support (This information is licensed under the terms of the Open Government Licence. 2011 http://www.nationalarchives.gov.uk/doc/opengovernment-licence/version/2http://infuse.ukdataservice.ac.uk (accessed 11 July 2016).

25. Diaz-Valencia PA, Bougnères $P$, Valleron AJ. Global epidemiology of type 1 diabetes in young adults and adults: a systematic review. BMC Public Health 2015;15:255-70.

26. Soltesz G, Patterson CC, Dahlquist G. EURODIAB Study Group. Worldwide childhood type 1 diabetes incidence--what can we learn from epidemiology? Pediatr Diabetes 2007;8(Suppl 6):6-14.

27. Thomas NJ, Jones SE, Weedon MN, et al. Frequency and phenotype of type 1 diabetes in the first six decades of life: a cross-sectional, genetically stratified survival analysis from UK Biobank. Lancet Diabetes Endocrinol 2018;6.

28. Dabelea D, Stafford JM, Mayer-Davis EJ, et al. Association of Type 1 Diabetes vs Type 2 Diabetes Diagnosed During Childhood and Adolescence With Complications During Teenage Years and Young Adulthood. JAMA 2017;317:825-35.

29. Ferrara CT, Geyer SM, Liu YF, et al. Excess BMI in childhood: a modifiable risk factor for type 1 diabetes development? Diabetes Care 2017;40:698-701.

30. Karjalainen J, Salmela P, Ilonen J, et al. A comparison of childhood and adult type I diabetes mellitus. N Engl J Med 1989;320:881-6.

31. Sabbah E, Savola K, Ebeling T, et al. Genetic, autoimmune, and clinical characteristics of childhood- and adult-onset type 1 diabetes. Diabetes Care 2000;23:1326-32.

32. National Paediatric Diabetes Audit. National Diabetes Paediatric Audit 2012-2015 Report 2: hospital admissions and complications: Royal College of Paediatrics and Child Health, 2017

33. Pinkey JH, Bingley PJ, Sawtell PA, et al. Presentation and progress of childhood diabetes mellitus: a prospective population-based study. The Bart's-Oxford Study Group. Diabetologia 1994;37:70-4.

34. Alvi NS, Davies P, Kirk JM, et al. Diabetic ketoacidosis in Asian children. Arch Dis Child 2001;85:60-1.

35. Usher-Smith JA, Thompson M, Ercole A, et al. Variation between countries in the frequency of diabetic ketoacidosis at first presentation of type 1 diabetes in children: a systematic review. Diabetologia 2012;55:2878-94. 
36. Cherubini V, Skrami E, Ferrito L, et al. High frequency of diabetic ketoacidosis at diagnosis of type 1 diabetes in Italian children: a nationwide longitudinal study, 2004-2013. Sci Rep 2016;6:38844.

37. Vanelli M, Chiari G, Lacava S, et al. Campaign for diabetic ketoacidosis prevention still effective 8 years later. Diabetes Care 2007;30:e12.

38. Rewers A, Klingensmith G, Davis C, et al. Presence of diabetic ketoacidosis at diagnosis of diabetes mellitus in youth: the Search for Diabetes in Youth Study. Pediatrics 2008;121:e1258-66.

39. Lokulo-Sodipe K, Moon RJ, Edge JA, et al. Identifying targets to reduce the incidence of diabetic ketoacidosis at diagnosis of type 1 diabetes in the UK. Arch Dis Child 2014;99:438-42.

40. Choleau C, Maitre J, Filipovic Pierucci A, et al. Ketoacidosis at diagnosis of type 1 diabetes in French children and adolescents. Diabetes Metab 2014;40:137-42.

41. National Paediatric Diabetes Audit Project Board. National Diabetes Paediatric Audit Report 2011-12: Part 2 hospital admissions and complications: Royal College of Paediatrics and Child Health, 2014.

42. Sundaram PC, Day E, Kirk JM. Delayed diagnosis in type 1 diabetes mellitus. Arch Dis Child 2009;94:151-2.

43. Usher-Smith JA, Thompson MJ, Sharp SJ, et al. Factors associated with the presence of diabetic ketoacidosis at diagnosis of diabetes in children and young adults: a systematic review. BMJ 2011;343:d4092.

44. Gorus FK, Goubert P, Semakula C, et al. IA-2-autoantibodies complement GAD65-autoantibodies in new-onset IDDM patients and help predict impending diabetes in their siblings. The Belgian Diabetes Registry. Diabetologia 1997;40:95-9.

45. Long AE, Gillespie KM, Rokni S, et al. Rising incidence of type 1 diabetes is associated with altered immunophenotype at diagnosis. Diabetes 2012;61:683-6.

46. Perchard R, MacDonald D, Say J, et al. Islet autoantibody status in a multi-ethnic UK clinic cohort of children presenting with diabetes. Arch Dis Child 2015;100:348-52.

47. Pihoker C, Gilliam LK, Hampe CS, et al. Autoantibodies in diabetes. Diabetes 2005;54(Suppl 2):S52-61.

48. Kawasaki E, Takino H, Yano M, et al. Autoantibodies to glutamic acid decarboxylase in patients with IDDM and autoimmune thyroid disease. Diabetes 1994;43:80-6.

49. Bosi E, Boulware DC, Becker DJ, et al. Impact of Age and Antibody Type on Progression From Single to Multiple Autoantibodies in Type 1 Diabetes Relatives. J Clin Endocrinol Metab 2017;102:2881-6.
50. Parikka V, Näntö-Salonen K, Saarinen M, et al. Early seroconversion and rapidly increasing autoantibody concentrations predict prepubertal manifestation of type 1 diabetes in children at genetic risk. Diabetologia 2012;55:1926-36.

51. Ziegler AG, Bonifacio E.BABYDIAB-BABYDIET Study Group. Agerelated islet autoantibody incidence in offspring of patients with type 1 diabetes. Diabetologia 2012;55:1937-43.

52. Naik RG, Palmer JP. Latent autoimmune diabetes in adults (LADA). Rev Endocr Metab Disord 2003;4:233-41.

53. Maruyama T, Nakagawa T, Kasuga A, et al. Heterogeneity among patients with latent autoimmune diabetes in adults. Diabetes Metab Res Rev 2011;27:971-4

54. Buzzetti R, Zampetti S, Maddaloni E. Adult-onset autoimmune diabetes: current knowledge and implications for management. Nat Rev Endocrinol 2017;13:674-86.

55. Palmer JP, Hampe CS, Chiu $\mathrm{H}$, et al. Is latent autoimmune diabetes in adults distinct from type 1 diabetes or just type 1 diabetes at an older age? Diabetes 2005;54:S62-7.

56. Williams AJ, Bingley PJ. Worth the wait: type 1 diabetes prospective birth cohort studies enter adolescence. Diabetologia 2012;55:1873-6.

57. Wod M, Yderstræde KB, Halekoh U, et al. Metabolic risk profiles in diabetes stratified according to age at onset, islet autoimmunity and fasting C-peptide. Diabetes Res Clin Pract 2017;134:62-71.

58. Pietropaolo M, Towns R, Eisenbarth GS. Humoral autoimmunity in type 1 diabetes: prediction, significance, and detection of distinct disease subtypes. Cold Spring Harb Perspect Med 2012;2:a012831.

59. McLaughlin KA, Richardson CC, Ravishankar A, et al. Identification of Tetraspanin-7 as a Target of Autoantibodies in Type 1 Diabetes. Diabetes 2016;65:1690-8.

60. Walther D, Eugster A, Jergens S, et al. Tetraspanin 7 autoantibodies in type 1 diabetes. Diabetologia 2016;59:1973-6.

61. Borg H, Gottsäter A, Fernlund P, et al. A 12-year prospective study of the relationship between islet antibodies and beta-cell function at and after the diagnosis in patients with adult-onset diabetes. Diabetes 2002;51:1754-62.

62. American Diabetes Association. Standards of medical care in diabetes-2016 abridged for primary care providers. Clin Diabetes 2016;34:3-21. 